\title{
Bio-inspired mechanically-adaptive nanocomposites derived from cotton cellulose whiskers $\dagger$
}

\author{
Kadhiravan Shanmuganathan, ${ }^{a}$ Jeffrey R. Capadona, ${ }^{b c}$ Stuart J. Rowan*abd and Christoph Weder*ae
}

A new series of biomimetic, stimuli-responsive nanocomposites, which change their mechanical properties upon exposure to physiological conditions, was investigated. The materials were produced by introducing percolating networks of cellulose whiskers isolated from cotton into poly(vinyl acetate). Below the glass-transition temperature $\left(T_{\mathrm{g}} \sim 63^{\circ} \mathrm{C}\right)$, the tensile storage moduli $\left(E^{\prime}\right)$ of the dry nanocomposites increased two fold, from $2 \mathrm{GPa}$ for the neat polymer to $4 \mathrm{GPa}$ for a nanocomposite with $16.5 \% \mathrm{v} / \mathrm{v}$ whiskers. The relative reinforcement was more significant above $T_{\mathrm{g}}$, where $E^{\prime}$ was increased nearly 40 fold, from $\sim 1.2 \mathrm{MPa}$ to $\sim 45 \mathrm{MPa}$. Upon exposure to emulated physiological conditions (immersion in artificial cerebrospinal fluid at $37^{\circ} \mathrm{C}$ ) all nanocomposites showed a pronounced decrease in $E^{\prime}$, for example to $5 \mathrm{MPa}$ for the $16.5 \% \mathrm{v} / \mathrm{v}$ whisker nanocomposites with only about $28 \% \mathrm{w} / \mathrm{w}$ swelling. This is a significant reduction in the amount of swelling required to decrease the $E^{\prime}$, compared to earlier material versions based on cellulose whiskers with higher surface charge density; the decreased swelling may be a considerable advantage for the intended use of these materials as adaptive substrates for intracortical electrodes and other biomedical applications.

\section{Introduction}

Materials that respond to stimuli in a selective and controlled manner are of significant interest for use in several biomedical applications like drug delivery, ${ }^{1}$ cell culture, ${ }^{2}$ and bioseparation ${ }^{3}$ as well as other applications such as sensors and actuators, ${ }^{4}$ smart clothing ${ }^{5}$ etc. Electro-rheological materials ${ }^{6}$ and certain hydrogels ${ }^{7,8}$ (which rely on a sol-gel transition) and shape memory polymers ${ }^{9}$ are typical examples of stimuli responsive polymeric materials which change their physical shape or mechanical properties in response to environmental stimuli. However, while most of these mechano-responsive materials exhibit viscosity/modulus changes of several orders of magnitude, they are not very rigid (modulus in the KPa to MPa range). Examples of much stiffer materials that exhibit such morphing mechanical behavior are quite limited.

We recently developed a new family of mechanically dynamic polymer nanocomposites ${ }^{10}$ that were inspired by the stimuliresponsive dermis of sea cucumbers. These creatures have the fascinating ability to rapidly and reversibly alter the stiffness of their inner dermis in response to a threat. ${ }^{11}$ In recent studies it has

${ }^{a}$ Department of Macromolecular Science \& Engineering, Case Western Reserve University (CWRU), 2100 Adelbert Road, Cleveland, Ohio 44106-7202,USA. E-mail: stuart.rowan@case.edu

${ }^{b}$ Department of Biomedical Engineering, CWRU, Cleveland, OH, USA

${ }^{c}$ Rehabilitation Research and Development, Louis Stokes Cleveland DVA Medical Center, Cleveland, OH, USA

${ }^{d}$ Department of Chemistry, CWRU, Cleveland, OH, USA

'Adolphe Merkle Institute and Fribourg Center for Nanomaterials, University of Fribourg, CH-1700 Fribourg, Switzerland. E-mail christoph.weder@unifr.ch been proposed that this dynamic mechanical behavior is achieved through a nanocomposite architecture, where a viscoelastic matrix is reinforced with rigid, high-aspect ratio collagen fibrils. ${ }^{\mathbf{1 2}}$ The stiffness of the tissue is regulated by controlling the interactions, and therewith the stress transfer, between adjacent collagen fibrils by locally secreted proteins through either noncovalent ${ }^{13}$ or covalent ${ }^{14}$ bonds. Intrigued by this natural model, we have been investigating the possibility of creating synthetic nanocomposites that exhibit a similar architecture as well as a comparable morphing capability. In particular, we are interested in investigating the potential of such materials as adaptive intracortical electrodes, ${ }^{15}$ which are sufficiently rigid to allow for penetration of the pia mater during implantation of the device, ${ }^{16}$ but upon implantation and exposure to physiological conditions soften to more closely match the mechanical properties of the brain.

Our initial studies involved the use of cellulose nanofibers (also referred to as nanowhiskers or simply whiskers) as an alternative filler to the collagen found in the natural model. Cellulose whiskers can be obtained from a range of renewable bio-sources, including tunicates, ${ }^{17,18}$ wood, ${ }^{19}$ cotton $^{20}$ and sisal. ${ }^{21}$ Our initial studies in this area have primarily focused on the use of tunicate cellulose whiskers. The whiskers obtained from these sea creatures exhibit high stiffness (tensile modulus $\sim 130 \mathrm{GPa}$ ) and dimensions on the nanometre scale $(26 \mathrm{~nm} \times 2.2 \mu \mathrm{m}){ }^{22}$

Cellulose whiskers have a strong tendency for aggregation ${ }^{23-25}$ due to the high density of strongly interacting surface hydroxyl groups. If sulfuric acid is used for the hydrolysis of the 4bio-derived pulp, the isolated cellulose whiskers are decorated with a small number of sulfate groups. ${ }^{26}$ Good dispersion of these partially negatively charged cellulose whiskers can be achieved when the whisker-whisker hydrogen bonding interactions are "switched off" by competitive binding with a hydrogen-bond-forming solvent. ${ }^{10,24}$ 
Upon solvent removal, the interactions between the whiskers are "switched on" and they assemble into a percolating network. ${ }^{10}$ These strong hydrogen bonding whiskers have led to a significant enhancement in the tensile storage modulus $\left(E^{\prime}\right)$ of PEO-EPI (polyethylene oxide-co-epichlorohydrin) from $\sim 3.7 \mathrm{MPa}$ (neat) to $\sim 800 \mathrm{MPa}(19 \% \mathrm{v} / \mathrm{v}$ tunicate whiskers). Upon exposure to water, which acts as a chemical regulator and switches the hydrogen bonding between the whiskers within the polymer matrix "off"," a dramatic modulus reduction was achieved (e.g. from 800 to $20 \mathrm{MPa}$ for a composite comprising $19 \% \mathrm{v} / \mathrm{v}$ whiskers); when these nanocomposites were dried, the original stiffness was restored, which demonstrates the reversibility of the system. However, $E^{\prime}$ of the most rigid composition studied $(800 \mathrm{MPa})$ was lower than required for the targeted use in intracortical electrodes $(\sim 4 \mathrm{GPa})$. We therefore combined the switching mechanism with a chemically influenced thermal transition and discovered that nanocomposites based on poly(vinyl acetate) (PVAc) and cellulose whiskers display such a "dual" responsive behavior. Upon exposure to water or artificial cerebrospinal fluid (ACSF) at $37^{\circ} \mathrm{C}$, diffusion of water into the nanocomposites not only disengages the whisker network, but plasticization by water reduces the glass transition temperature $\left(T_{g}\right)$ of PVAc and the nanocomposites from $\sim 60$ to $\sim 20^{\circ} \mathrm{C}$, i.e. from above to below physiological temperature. This approach has afforded materials which exhibit a dramatic mechanical contrast of three orders of magnitude between the dry state at room temperature $\left(E^{\prime}=5.1 \mathrm{GPa}\right.$ for a nanocomposite with $16.5 \%$ $\mathrm{v} / \mathrm{v}$ tunicate whiskers) and the water- or ACSF-swollen state at $37{ }^{\circ} \mathrm{C}(\sim 12 \mathrm{MPa}) .{ }^{10}$ However, at this temperature, the water or ACSF take-up was very significant $(\sim 70-90 \% \mathrm{w} / \mathrm{w}$ for $16.5 \% \mathrm{v} / \mathrm{v}$ tunicate whiskers). With the goals of lowering the "soft" modulus of such nanocomposites, to reduce the level of swelling, and to explore the potential of using cellulose whiskers from a more accessible bio-source than tunicates, we embarked on the exploration of stimuli responsive nanocomposites using cotton cellulose whiskers $(\mathrm{CCW})$. As will be shown, CCWs exhibit properties which are suitable to achieve these goals.

\section{Experimental}

\section{Materials}

Poly(vinyl acetate) (PVAc, weight-average molecular weight, $M_{w}=113,000 \mathrm{~g} \mathrm{~mol}^{-1}$; density, $\delta=1.19 \mathrm{~g} \mathrm{~cm}^{-3}$ ) was purchased from Sigma-Aldrich. All other reagents were also purchased from Sigma-Aldrich and were used without further purification. Artificial cerebrospinal fluid was prepared by dissolving the following salts in $1 \mathrm{~L}$ of deionized water: ${ }^{27} \mathrm{NaCl}=7.25 \mathrm{~g}, \mathrm{KCl}=$ $0.22 \mathrm{~g}, \mathrm{NaHCO}_{3}=2.18 \mathrm{~g}, \mathrm{CaCl}_{2} \cdot 2 \mathrm{H}_{2} \mathrm{O}=0.29 \mathrm{~g}, \mathrm{KH}_{2} \mathrm{PO}_{4}=$ $0.17 \mathrm{~g}, \mathrm{MgSO}_{4} \cdot 7 \mathrm{H}_{2} \mathrm{O}=0.25 \mathrm{~g}, \mathrm{D}$-glucose $=1.80 \mathrm{~g}$.

\section{Preparation of polymer/cotton cellulose whisker nanocomposites}

Cellulose whiskers from cotton were isolated using the general procedure of Dong et al. ${ }^{28}$ with slight modifications as described in detail before. ${ }^{25}$ Lyophilized whiskers were dispersed in dimethyl formamide (DMF) at a concentration of $\sim 4 \mathrm{mg} \mathrm{mL}^{-1}$ by sonicating for 8-12 h. PVAc was dissolved in DMF at a concentration of $\sim 5 \% \mathrm{w} / \mathrm{w}$ by stirring for 4-6 h. Nanocomposites were prepared by combining the desired amounts (to yield materials containing $0-16 \% \mathrm{v} / \mathrm{v}$ whiskers) of the colloidal whisker dispersion and polymer solution, sonicating for $10 \mathrm{~min}$ and solutioncasting the resulting homogeneous mixture into Teflon ${ }^{\circledR}$ petri dishes. The dishes were placed into a vacuum oven $\left(65^{\circ} \mathrm{C}\right.$, 15 mbar, 1 week) to evaporate the solvent and dry the resulting films, before the materials were compression-moulded between spacers in a Carver laboratory press $\left(90{ }^{\circ} \mathrm{C}\right.$ at 0 psi for $2 \mathrm{~min}$, followed by an increase in pressure to 3000 psi for $15 \mathrm{~min}$ ) to yield 200-300 $\mu \mathrm{m}$ thin nanocomposite films. Neat PVAc films were also prepared in a similar manner to create reference films for mechanical testing. This method has been previously reported to produce homogeneous films free of phase separation. ${ }^{10}$

\section{Determination of charge density on cotton whiskers}

Cellulose whiskers with negatively charged sulfate groups $\left(\mathrm{ROSO}_{3}{ }^{-}\right)$were obtained via sulfuric acid hydrolysis of cotton. The charge density was determined by conductometric titration. In short, $4 \mathrm{~mL}$ of a cotton whisker/water dispersion of a concentration of $20.9 \mathrm{mg} \mathrm{mL} \mathrm{mL}^{-1}$ was added to $70 \mathrm{~mL}$ of deionized water and the dispersion was stirred. $\mathrm{pH}$ and conductivity probes were inserted into the colloidal suspension. To neutralize the acid groups, a $0.01 \mathrm{M} \mathrm{KOH}$ solution was added in steps of $50 \mu \mathrm{L}$ and the $\mathrm{pH}$ and conductivity of the solution were continuously recorded to determine the endpoint. From the volume of $\mathrm{KOH}$ required to neutralize the solution and the amount of whiskers, the charge density was determined.

\section{Dynamic mechanical analysis}

The mechanical properties of the nanocomposites were characterized by dynamic mechanical analysis (DMA, TA instruments Model Q800). Tests were conducted in tensile mode using a temperature sweep method $\left(23^{\circ} \mathrm{C}\right.$ to $\left.90{ }^{\circ} \mathrm{C}\right)$ at a fixed frequency of $1 \mathrm{~Hz}$, and amplitude of strain $15 \mu \mathrm{m}$. In order to determine the tensile properties of the nanocomposite films in the wet state, samples were swollen in ACSF at $37^{\circ} \mathrm{C}$ for 1 week and tensile tests were conducted using a submersion clamp, which allowed us to keep the samples immersed in ACSF during testing; here a temperature sweep in the range of $23^{\circ} \mathrm{C}$ to $50^{\circ} \mathrm{C}$ was done. All samples were dried in vacuum at $60^{\circ} \mathrm{C}$ for $16-18 \mathrm{~h}$ prior to DMA testing or swelling experiments (except, of course, for the analysis of swollen samples).

\section{Swelling behavior}

Prior to DMA testing of ACSF swollen samples, the degree of swelling was determined by measuring the weight of the samples pre- and post-swelling:

$$
\frac{\text { Mass of wet sample }- \text { Mass of dry sample }}{\text { Mass of dry sample }} \times 100
$$

\section{Results and discussion}

\section{Physical properties of cotton cellulose whiskers}

Sulfuric acid hydrolysis of Whatman filter paper yields cellulose crystals with a typical diameter of $c a$. 10-20 nm, a length between $100-250 \mathrm{~nm}$ and an average aspect ratio of $(\sim 10)$, which is much 


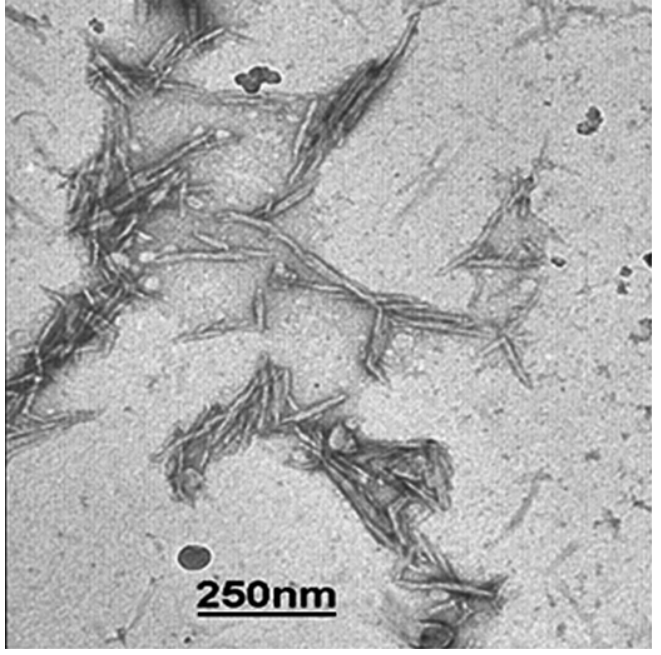

Fig. 1 Transmission electron microscopy images of cotton cellulose whiskers. The sample was produced by depositing a drop of a $0.2 \% \mathrm{w} / \mathrm{w}$ cotton cellulose whisker dispersion in DMF onto a carbon-coated copper grid.

lower than that of tunicate cellulose (70-100). Fig. 1 shows transmission electron microscopic images of the CCWs prepared here. CCWs (tensile modulus $\sim 57-105 \mathrm{GPa}^{29}$ ) also exhibit a lower stiffness than tunicate whiskers (tensile modulus $\sim 130 \mathrm{GPa}){ }^{22}$ Sulfate groups on the cotton whiskers cause electrostatic repulsion between the whiskers and are important for their good dispersibility in many solvents like water, $\mathrm{N}, \mathrm{N}$-dimethyl formamide, dimethyl sulfoxide and $\mathrm{N}$-methyl pyrrolidone. ${ }^{24,30}$ The density of the sulfate groups of the present CCWs was measured by conductometric titrations to be $\sim 31 \mathrm{mmol} \mathrm{kg}^{-1}$ (ESI $\dagger$ Fig. S1). This is significantly lower than that of tunicate cellulose whiskers $\left(\sim 85 \mathrm{mmol} \mathrm{kg}^{-1}\right)$ used in our previous studies; the difference can be attributed to the milder hydrolysis conditions employed for the cotton cellulose (the application of conditions normally used for the hydrolysis of tunicates leads to degradation of CCWs): the initial concentration of the aqueous cellulose pulp used for hydrolysis of cotton cellulose $(\sim 2 \% \mathrm{w} / \mathrm{w})$ was about twice that of tunicate cellulose $(\sim 1 \% \mathrm{w} / \mathrm{w})$ and the final acid/water ratio used in the hydrolysis of cotton cellulose (acid weight fraction 55\%) was lower than that used in the case of tunicate cellulose $(75 \%)$.

\section{Mechanical properties of dry PVAc/cotton cellulose whisker nanocomposites}

Nanocomposite films composed of 0 to $16.5 \% \mathrm{v} / \mathrm{v}$ CCWs in PVAc were produced by solution-casting from DMF and subsequent compression molding (see Experimental Section for details). The thermo-mechanical properties of these materials were established by dynamic mechanical analysis (DMA). Temperature-dependent tensile storage moduli $\left(E^{\prime}\right)$ of PVAc/CCW nanocomposites in the dry state are shown in Fig. 2a. At ambient temperature (at $25^{\circ} \mathrm{C}$ ) the neat PVAc matrix is in a glassy state and displays an $E^{\prime}$ of $\sim 2 \mathrm{GPa}$; upon increasing the temperature, the stiffness displayed a drastic reduction, to reach $\sim 1.2 \mathrm{MPa}$ around $75-80^{\circ} \mathrm{C}$. This is related to transition to the rubbery regime upon heating the material above $T_{g}$, which is at $c a .63^{\circ} \mathrm{C}$,
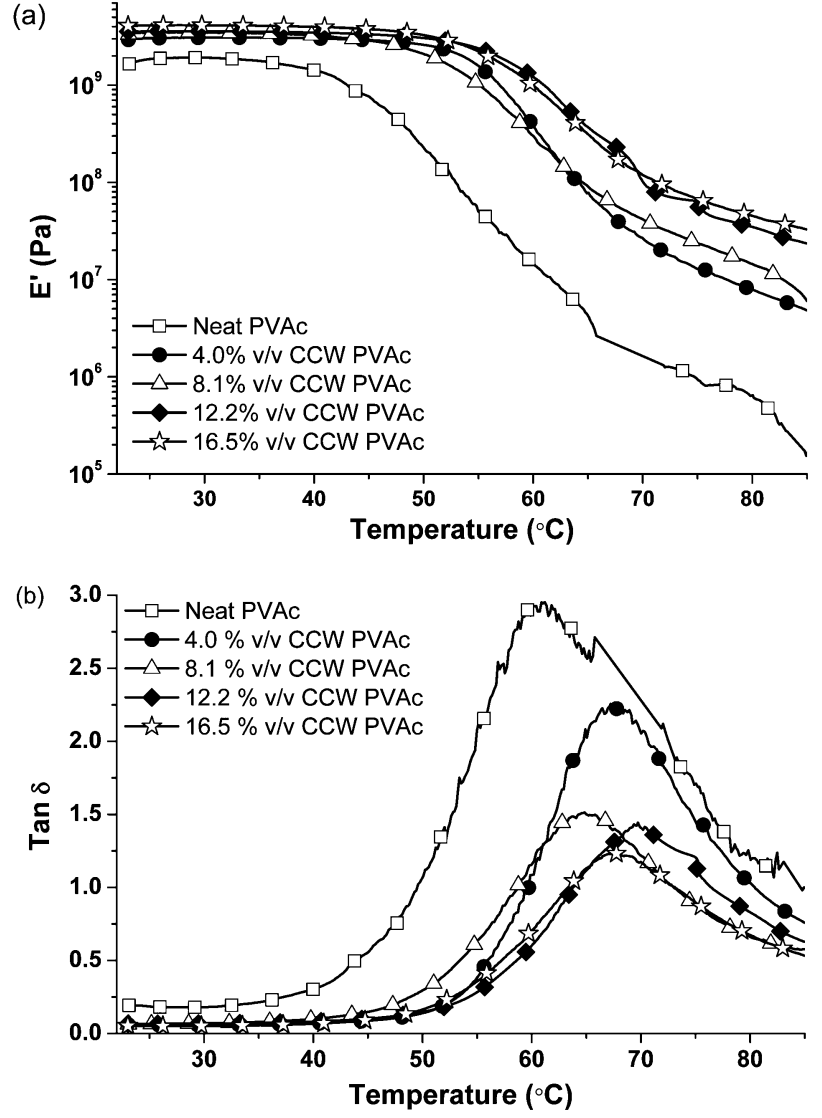

Fig. 2 (a) Tensile storage moduli $E^{\prime}$ of dry films of neat PVAc and $\mathrm{PVAc} /$ cotton cellulose whisker $(\mathrm{CCW})$ nanocomposites as a function of temperature and composition. Data were acquired by DMA. (b) Loss tangent $v s$. temperature plots of DMA sweeps shown in (a).

as seen from the DMA loss tangent (tan $\delta$ ) (Fig. 2b). Incorporation of cellulose whiskers led to a modest increase in the tensile storage modulus below $T_{g}$. $E^{\prime}$ increased from $2 \mathrm{GPa}$ to $4 \mathrm{GPa}$ for a nanocomposite comprising $16.5 \% \mathrm{v} / \mathrm{v}$ cellulose whiskers. This is typical of glassy matrices reinforced with rigid fillers and is consistent with other studies on cellulose whisker nanocomposites. ${ }^{31,32}$ The peak displayed by the $\tan \delta v$ s. temperature traces of the nanocomposites (Fig. 2b) became broader upon introduction of the CCWs and the peak position slightly shifted towards higher temperatures by about $5-7^{\circ} \mathrm{C}$. Tan $\delta$ is the ratio of loss modulus to storage modulus of the material, and is indicative of its damping behavior. A peak in the $\tan \delta$ vs. temperature trace reflects a loss of energy due to the relaxation processes in polymeric materials, and in the case of the present materials is related to the glass transition. The peak temperature $\left(T_{\alpha}\right)$ corresponds to the transition temperature and the intensity $\left(I_{\alpha}\right)$ is related to the magnitude of the relaxation. ${ }^{33}$ Incorporation of whiskers led to a significant reduction in peak intensity, indicating a lower magnitude of chain relaxation. This can be attributed to polymer-whisker interactions through hydrogen bonding. This effect appears also to be responsible for the fact that $T_{\alpha}$ slightly increased with increasing content of cellulose whiskers. The same trend has been previously reported, and was attributed to interactions between the matrix polymer and the polar surface of the cellulose.$^{34}$ Of particular interest in these 
celluose whisker nanocomposites is the reinforcement that can be observed well above $T_{\mathrm{g}}$ (Fig. 2a). When incorporated in a concentration that allows for the formation of a rigid, percolating network (which relies on strong hydrogen bonding for stress transfer among the whiskers), these whiskers lead to significant reinforcement of the soft rubbery matrix. In the case of the CCW-based nanocomposites investigated here (Fig. 2a), $E^{\prime}$ was increased from about 1.2 $\mathrm{MPa}$ (neat polymer) to about $45 \mathrm{MPa}(16.5 \% \mathrm{v} / \mathrm{v} \mathrm{CCW})$ at $82^{\circ} \mathrm{C}$.

\section{Swelling behaviour of PVAc/cotton cellulose whisker nanocomposites}

In continuation of our efforts ${ }^{10}$ to develop mechanically dynamic substrates for adaptive intracortical electrodes, we were interested in the chemo-responsive nature of the PVAc/CCW nanocomposites. Hence we determined the swelling behavior of these nanocomposites in emulated physiological conditions (immersion in artificial cerebrospinal fluid, ACSF, at $37^{\circ} \mathrm{C}$ ). The swelling in ACSF at $37^{\circ} \mathrm{C}$ (determined according to eqn (1)) increased steadily with the whisker content (Fig. 3). This effect can be attributed to the increased hydrophilicity of the nanocomposite on account of the presence of cellulose whiskers. Previous swelling studies of PVAc/sisal whisker nanocomposites at room temperature and $98 \% \mathrm{RH}$ demonstrated that the swelling ratio of PVAc initially increases with the addition of whiskers but becomes approximately constant at higher concentrations of whiskers $(5-10 \% \mathrm{w} / \mathrm{w}) .{ }^{21}$ This is different than what we observe here. However it should be noted that our swelling temperature $\left(37{ }^{\circ} \mathrm{C}\right)$, source of whiskers, solvent, and range of whisker concentration studied is much different. Interestingly, a direct comparison (similar whisker content and identical swelling conditions) of this study and our previous one with tunicate whiskers shows that the present CCW-containing materials swell much less than the analogous PVAc/tunicate whisker nanocomposites investigated before ${ }^{10}$ (data included in Fig. 3 for comparison). For example, the $\mathrm{PVAc} / \mathrm{CCW}$ nanocomposite comprising $16.5 \% \mathrm{v} / \mathrm{v}$ whiskers displayed a degree of swelling of $\sim 28 \%$, which is $\sim 1 / 3$ that of a corresponding tunicate whisker

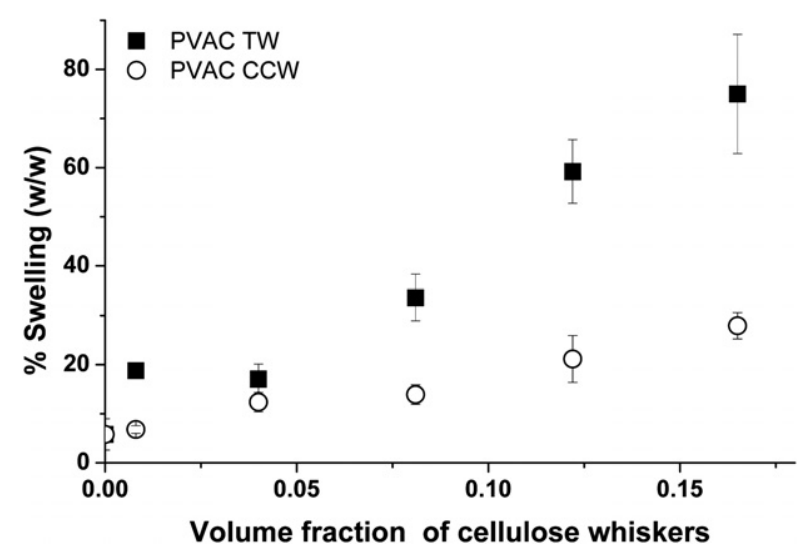

Fig. 3 Swelling of PVAc/cotton cellulose whisker and PVAc/tunicate whisker nanocomposites. Solvent uptake as a function of cellulose whisker volume fraction upon immersion in $\mathrm{ACSF}$ at $37^{\circ} \mathrm{C}$ for 1 week (to equilibration). Data points represent averages $(N=3-5) \pm$ standard deviation measurements. nanocomposite. Apart from being derived from a different source and having different dimensions, the major difference between the tunicate and cotton cellulose whiskers used in our studies is the density of charged sulfate groups (vide supra). In view of the well-established correlation between water uptake and concentration of ionic groups in ionic polymer membranes, ${ }^{35}$ it is plausible that the very desirable, low degree of swelling displayed by the present $\mathrm{CCW}$ nanocomposites is related to the lower sulfate charge density of the whiskers employed.

\section{Mechanical properties of ACSF-swollen PVAc/cotton whisker cellulose nanocomposites}

Fig. 4a shows the temperature-dependent tensile storage moduli $E^{\prime}$ of neat PVAc and PVAc/cotton cellulose whisker nanocomposite films that had been immersed in ACSF at $37^{\circ} \mathrm{C}$ for 1 week (i.e. to equilibrium) before being tested in a DMA set-up that allowed the samples to be kept immersed in ACSF during the tests. The $E^{\prime}$ dropped drastically as the temperature was increased from ambient temperature to $37^{\circ} \mathrm{C}$ and beyond. At $37{ }^{\circ} \mathrm{C}$, the physiological temperature of interest, $E^{\prime}$ of nanocomposites with higher whisker content $(12.2-16.5 \% \mathrm{v} / \mathrm{v})$ was about $5 \mathrm{MPa}$, while that of neat PVAc was close to $1 \mathrm{MPa}$. Thus, compared to the dry state at room temperature $\left(E^{\prime} \sim 4 \mathrm{GPa}\right)$
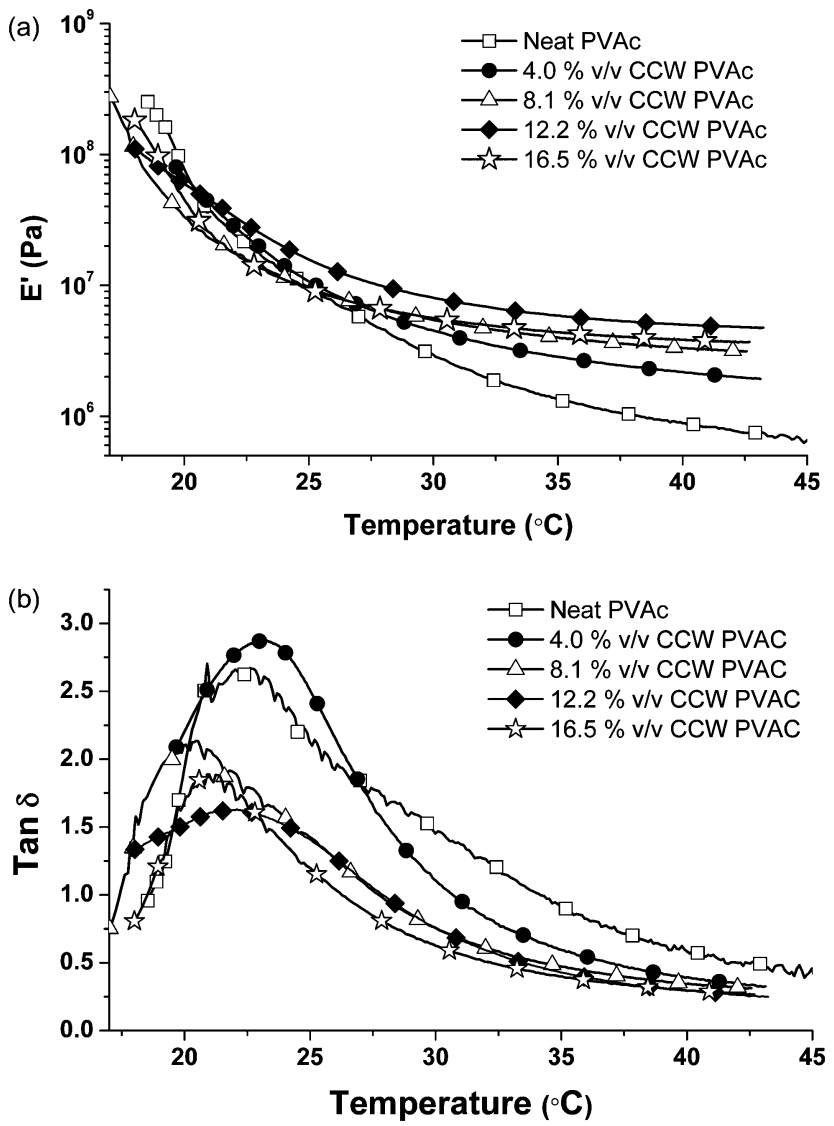

Fig. 4 (a) Tensile storage moduli $E^{\prime}$ of ACSF-swollen films (after immersion in ACSF at $37{ }^{\circ} \mathrm{C}$ for a week) of neat PVAc and PVAc/cotton cellulose whisker $(\mathrm{CCW})$ nanocomposites as a function of temperature and composition. Data were acquired by DMA. (b) Loss tangent vs. temperature plots of DMA sweeps shown in (a). 
a modulus reduction of three orders of magnitude can be achieved with the materials studied here. As reported earlier, this significant dynamic modulus contrast is a consequence of the combined effect of thermal and chemical stimuli. Water uptake plasticises PVAc and reduces the $T_{\mathrm{g}}$ of neat PVAc and the PVAcbased nanocomposites from $\sim 65$ to $\sim 21^{\circ} \mathrm{C}$ (Fig. $4 \mathrm{~b}$ ); at the same time it 'switches off' the whisker-whisker interactions through competitive hydrogen bonding. This reasoning is further supported by the comparison of the modulus data of dry and wet nanocomposites in the context of two classical models for short fiber composites namely, the Halpin Kardos and the percolation model. The detailed theoretical framework for these models can be found elsewhere ${ }^{36-38}$ and we provide here only a brief outline and summary of their underlying assumptions. The Halpin Kardos model ${ }^{36}$ assumes that the nanocomposites are quasiisotropic and equivalent to the superposition of four plies, where the nanofibers within each ply are parallel to one another and the directors of the plies are oriented towards each other at particular angles $\left(-45^{\circ}, 0^{\circ}, 45^{\circ}\right.$, and $\left.90^{\circ}\right)$. In this model the nanofiller particles are assumed to be homogeneously dispersed in a continuous matrix with no interactions between them. The modulus of the individual plies in the longitudinal and transverse directions are derived from Halpin Tsai equations, ${ }^{39}$

$$
\begin{gathered}
E_{L}^{\prime}=E_{s}^{\prime}\left(1+2(A) \eta_{L} \phi_{r}\right) /\left(1-\eta_{L} \phi_{r}\right) \text { and } \\
E^{\prime}{ }_{T}=E^{\prime}{ }_{s}\left(1+2 \eta_{T} \phi_{r}\right) /\left(1-\eta_{T} \phi_{r}\right)
\end{gathered}
$$

where $\eta_{L}=\left(\left(E_{l r} / E_{S}\right)-1\right) /\left(\left(E_{l r} / E_{S}\right)+2 A\right)$, and

$$
\eta_{T}=\left(\left(E_{t r} / E_{S}\right)-1\right) /\left(\left(E_{t r} / E_{s}\right)+2\right) \text {. }
$$

and the tensile storage modulus of the nanocomposite is given by

$$
E^{\prime}=4 U_{5}\left(U_{1}-U_{5}\right) / U_{1}
$$

$$
\begin{aligned}
& \text { with } U_{1}=1 / 8\left(3 Q_{11}+3 Q_{22}+2 Q_{12}+4 Q_{66}\right) \\
& \qquad \begin{array}{c}
U_{5}=1 / 8\left(Q_{11}+Q_{22}-2 Q_{12}+4 Q_{66}\right) \\
Q_{11}=E^{\prime}{ }_{L} /\left(1-\nu_{12} \nu_{21}\right) \\
Q_{22}=E^{\prime}{ }_{T}\left(1-\nu_{12} \nu_{21}\right) \\
Q_{12}=\nu_{12} Q_{22}=\nu_{21} Q_{11} \\
Q_{66}=G_{12}^{\prime} ;
\end{array}
\end{aligned}
$$

where $\nu_{12}=\phi_{r} \nu_{\mathrm{r}}+\phi_{s} \nu_{\mathrm{s}} ; G^{\prime}{ }_{12}=G_{s}^{\prime}\left(1+\eta \phi_{r}\right) /\left(1-\eta \phi_{r}\right) ; \eta=\left(G_{r}^{\prime} / G_{S}^{\prime}\right.$ $-1) /\left(G_{r}^{\prime} / G_{s}^{\prime}+1\right)$ and $\nu$ is the Poisson's ratio (defined above as $0.3), G^{\prime}$ is the shear modulus and $\phi$ is equal to the volume fraction of the phase (subscripts $r$ and $s$ refer to the rigid nanofiller and soft polymer phases, respectively). Thus, the modulus of the nanocomposites depends on the moduli and the volume fractions of nanofiller and matrix and the geometry of the filler.

The percolation model of Ouali, ${ }^{38}$ derived from the parallelseries model of Takayanagi, ${ }^{37}$ assumes the filler particles do strongly interact with each other to form a network; under conditions where the matrix is too soft (i.e. above $T_{\mathrm{g}}$ ) the modulus of the percolating rigid nanofiller network is assumed to be the primary factor that governs the modulus of the composite. The model expressed $E^{\prime}$ by:

$$
E^{\prime}=\frac{\left(1-2 \psi+\psi X_{r}\right) E^{\prime}{ }_{s} E_{r}^{\prime}+\left(1-X_{r}\right) \psi E^{\prime}{ }_{r}{ }^{2^{\prime}}}{\left(1-X_{r}\right) E^{\prime}{ }_{r}+\left(X_{r}-\psi\right) E^{\prime}{ }_{s}}
$$

Where $\psi$ is the percolating volume fraction of nanofibers that participate in the load transfer, which according to percolation theory is:

$$
\psi=X_{r}\left(\frac{X_{r}-X_{c}}{1-X_{c}}\right)^{0.4}
$$

Where $X_{r} \geq X_{c}$ and $X_{c} \geq 0.7 / A$ ( $A$ is the aspect ratio of the nanofibers) is the critical nanofiber volume fraction needed for percolation. ${ }^{40}$

Fig. 5 shows the experimental data and the theoretical values predicted by these models on the basis of parameters that can be independently determined $\left(E_{\mathrm{s}}^{\prime}=1.2 \mathrm{MPa}, A=10.5, E_{\mathrm{r}}^{\prime}=650\right.$ $\mathrm{MPa},{ }^{23,24} E^{\prime}{ }_{l r}=105 \mathrm{GPa},{ }^{29} E^{\prime}{ }_{t r}=5 \mathrm{GPa}, G_{\mathrm{r}}=1.77 \mathrm{GPa}, \nu_{s}=0.3$, and $\left.\nu_{\mathrm{r}}=0.5\right) .{ }^{39}$ The moduli of the dry PVAc/cotton cellulose nanocomposites at $82{ }^{\circ} \mathrm{C}$ (i.e. well above $T_{\mathrm{g}}$ ) follow the prediction of the percolation model quite well at higher volume fraction of whiskers, while at a whisker density of $4 \% \mathrm{v} / \mathrm{v}$ (i.e., below the percolation threshold), the experimental data exceed predicted values. This is consistent with previous studies that discuss the failure of the percolation model to accurately predict the modulus of nanocomposites below the percolation threshold. ${ }^{41}$ Additionally, the moduli of the corresponding ACSF-swollen nanocomposites fall well below the percolation model showing a gradually increasing trend as that of composites with noninteracting fillers. Though the modulus of the neat PVAc is

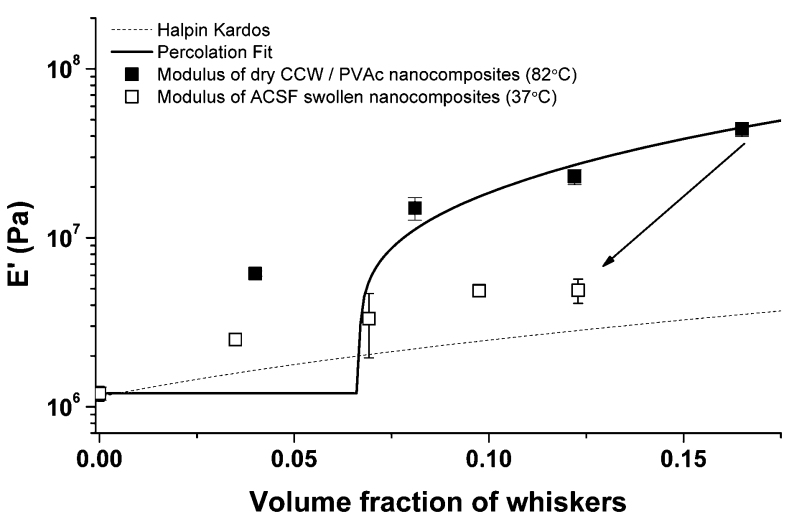

Fig. 5 Tensile storage moduli $E^{\prime}$ of neat PVAc and PVAc/cotton cellulose whisker nanocomposites (CCW) in the dry state at $82{ }^{\circ} \mathrm{C}$, and ACSF-swollen state (after immersion in ACSF at $37^{\circ} \mathrm{C}$ for a week) at $37^{\circ} \mathrm{C}$. Lines show the values predicted by the percolation (solid) and the Halpin-Kardos (dashed) models. Data of swollen samples are at a lower volume fraction compared to their dry state due to solvent uptake. Data points represent averages $(N=3-5) \pm$ standard deviation measurements. 
virtually the same under both conditions ( $\sim 1.2 \mathrm{MPa})$, the moduli of the nanocomposites differ by up to an order of magnitude. For example at $16.5 \% \mathrm{v} / \mathrm{v}$ of whiskers, the $E^{\prime}$ at $82{ }^{\circ} \mathrm{C}$ dropped from $\sim 45 \mathrm{MPa}$ to $\sim 5 \mathrm{MPa}$ upon swelling in ACSF. This suggests that upon exposure to a chemical stimulus, in addition to plasticization of the matrix, the hydrogen bonding interactions between whiskers are disrupted. Assuming a complete disengagement of the whisker network one would expect the moduli to fit the Halpin Kardos model. However, Fig. 5 shows that the moduli of the ACSF-swollen CCW nanocomposites are slightly higher than the prediction by the Halpin Kardos model. It is at this time not possible to assess if this difference is related to incomplete dissociation of the whisker network upon exposure to ACSF, or if the origin is the limited accuracy of the parameters fed into the model. For example, previous studies give a rather broad range of 57-105 GPa for $E_{l r}^{\prime}{ }^{29}$ and no data for $E_{t r}^{\prime}, G_{\mathrm{r}}$, and $\nu_{r}$ are available for cotton cellulose whiskers, and values established for tunicate whiskers ${ }^{39}$ were used instead.

We have previously shown that the dramatic softening of PEO-EPI/tunicate whisker nanocomposites upon exposure to water is fully reversible (vide supra); the modulus is fully restored upon drying. ${ }^{10}$ Similar experiments carried out on the PVAc/cotton whisker nanocomposites showed a similar reversible response (ESI $\dagger$ Fig. S2). For example, at $80^{\circ} \mathrm{C}$, above $T_{\mathrm{g}}$, the dry nanocomposite has a modulus of 28-30 MPa that upon swelling with water drops to $c a$. $5 \mathrm{MPa}$. Drying the nanocomposite in a vacuum oven at $60{ }^{\circ} \mathrm{C}$ for two days results in restoration of the modulus of the film $(28-30 \mathrm{MPa})$. At $37{ }^{\circ} \mathrm{C}$, i.e. below $T_{\mathrm{g}}$ of the dry nanocomposite, a similar recovery is observed. That is, the original dry film had a modulus of $3.9 \mathrm{GPa}$ which drops to $5 \mathrm{MPa}$ upon exposure to an aqueous environment. Upon drying, the film's modulus returns to close to that of the original (3-3.5 GPa).

\section{Cotton cellulose vs. tunicate cellulose whiskers}

Fig. 6a compares the reinforcement offered by cotton cellulose whiskers and tunicate cellulose whiskers ${ }^{10}$ (reproduced here for comparison) for nanocomposites comprising $16.5 \% \mathrm{v} / \mathrm{v}$ of the respective nanofibers in a PVAc matrix. The modulus of the cotton cellulose nanocomposite below $T_{\mathrm{g}}$ is about $4 \mathrm{GPa}$, i.e., only slightly lower than that of the tunicate cellulose counterpart $\left(E^{\prime} \sim 5 \mathrm{GPa}\right)$. Above $T_{\mathrm{g}}$, the moduli differ by an order of magnitude ( $\sim 600$ vs. $\sim 45 \mathrm{MPa})$. This difference is consistent with previous findings for nanocomposites comprising the two whisker types ${ }^{10,25}$ (cotton cellulose whiskers have been known to display a less pronounced reinforcement than tunicate cellulose whiskers) and the fact that neat, solution-cast sheets (nanopapers) of cotton cellulose whiskers display a much lower stiffness than those produced from tunicate cellulose. However, the origin of this difference is unclear at this point; the difference in aspect ratio should not be a major factor, since both materials systems investigated are significantly above the threshold for percolation. In the ACSF swollen state, however, the difference between the two systems is narrowed; at $37^{\circ} \mathrm{C}$ the $\mathrm{CCW}$-based PVAc nanocomposite shows a modulus of $\sim 5 \mathrm{MPa}$, which is only slightly lower than that ( $\sim 12 \mathrm{MPa})$ of the tunicate cellulose based nanocomposite (Fig. 6b).
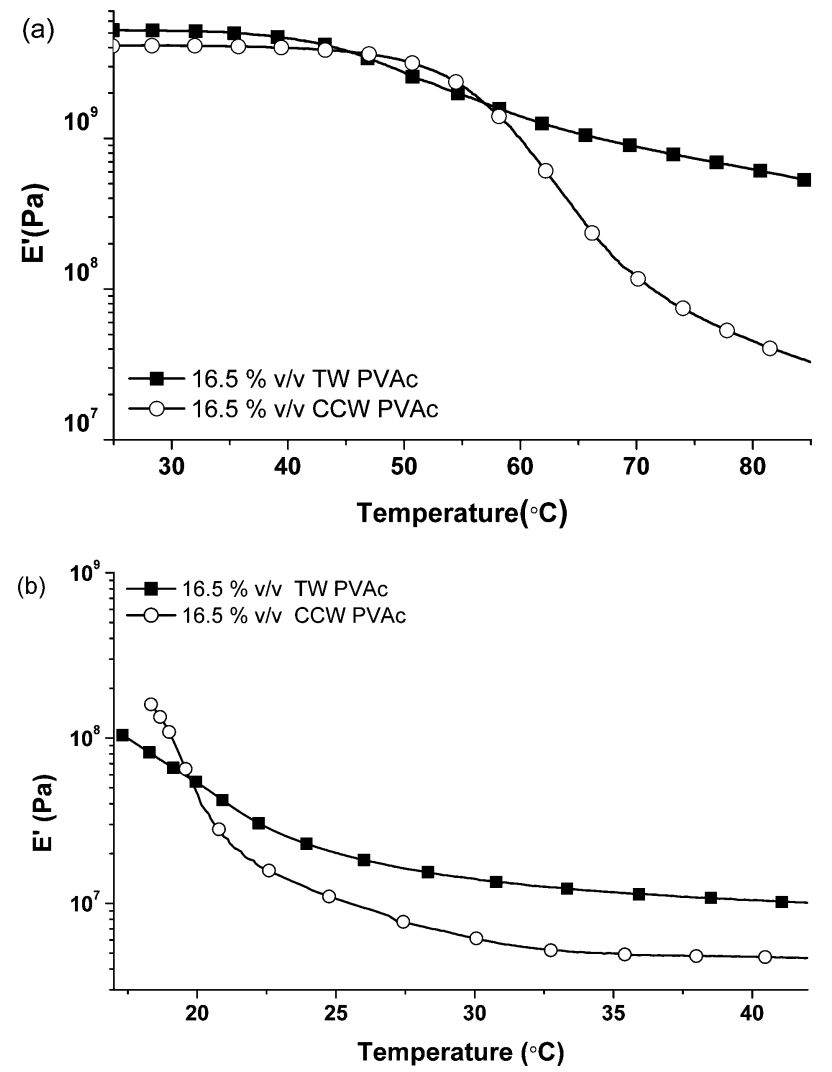

Fig. 6 Comparison of temperature-dependent tensile storage moduli $E^{\prime}$ of PVAc nanocomposites with $16.5 \% \mathrm{v} / \mathrm{v}$ tunicate whiskers (TW) or cotton cellulose whiskers (CCW) in (a) dry state and (b) swollen in ACSF at $37{ }^{\circ} \mathrm{C}$ for a week. Data of tunicate whisker nanocomposites are reproduced from ref. 10 for comparison.

Most importantly, the overall modulus contrast of a $16.5 \% \mathrm{v} / \mathrm{v}$ cotton cellulose PVAc nanocomposite between the dry state at $37^{\circ} \mathrm{C}$ and ACSF swollen state at $37^{\circ} \mathrm{C}$ is still three orders of magnitude (4 $\mathrm{GPa}$ to $5 \mathrm{MPa}$ ) and therewith comparable to that of a similar material based on tunicate cellulose whiskers (5 GPa to $12 \mathrm{MPa}$ ). This is of significant importance to the targeted application as adaptive substrates for intracortical electrodes, where an initial $E^{\prime}$ of $>4 \mathrm{GPa}$ is desirable to allow for the insertion of an electrode with typical dimensions into the cortex. ${ }^{42,43}$ As shown above, however, the aqueous swelling of the cotton-based materials is massively reduced, which represents a significant advantage over the tunicate-based nanocomposites.

\section{Conclusions}

In summary, nanocomposites of PVAc and cotton cellulose whiskers demonstrate a mechanically adaptive behavior in response to thermal and chemical stimuli. While the mechanical contrast in stiffness is almost similar to our earlier generation PVAc-tunicate whisker nanocomposites, the water uptake of these nanocomposites is significantly lower, presumably due to the lower surface charge density of cotton cellulose whiskers. This represents a significant advancement in our efforts to make adaptive substrates for intracortical electrodes. Moreover these nanocomposites can be produced by using cellulose whiskers 
isolated from cotton, which is a more readily accessible cellulose source than tunicates.

\section{Acknowledgements}

Financial support from the National Institute of Health under Grant No. R21NS053798-0, the Case School of Engineering (Ohio Innovation Incentive Fellowship to K.S.) and the Department of Veteran's Affairs Career Development Program (to J.R.C.) is gratefully acknowledged.

\section{Notes and references}

1 (a) D. Needham and M. W. Dewhirst, Adv. Drug Delivery Rev., 2001, 53, 285; (b) N. A. Peppas, J. Z. Hilt, A. Khademhosseini and R. Langer, Adv. Mater., 2006, 18, 1345; (c) Y. H. Kim, I. C. Kwon, Y. H. Bae and S. W. Kim, Macromolecules, 1995, 28, 939.

2 (a) T. Shimizu, M. Yamato, A. Kikuchi and T. Okano, Tissue Eng., 2001, 7, 141; (b) O. H. Kwon, A. Kikuchi, M. Yamato, Y. Sakurai and T. Okano, J. Biomed. Mater. Res., 2000, 50, 82.

3 H. Lee and T. Gwan Park, Biotechnol. Prog., 1998, 14, 508.

4 (a) R. Pelrine, R. Kornbluh, Q. B. Pei and J. Joseph, Science, 2000, 287, 836; (b) V. H. Ebron, Z. W. Yang, D. J. Seyer, M. E. Kozlov, J. Y. Oh, H. Xie, J. Razal, L. J. Hall, J. P. Ferraris, A. G. MacDiarmid and R. H. Baughman, Science, 2006, 311, 1580.

5 N. S. Save, M. Jassal and A. K. Agrawal, J. Ind. Text., 2005, 34, 139.

6 (a) J. D. Carlson, A. F. Sprecher and H. Conrad, in Proceedings of the Second International Conference on ER Fluids; Technomic Publishing Co. Ltd., Lancaster, PA, 1989; (b) K. Minagawa and K. Koyama, Curr. Org. Chem., 2005, 9, 1643.

7 T. Suzuki, S. Shinkai and K. Sada, Adv. Mater., 2006, 18, 1043.

8 Y. Chen and M. Yi, Radiat. Phys. Chem., 2001, 61, 65.

9 (a) A. Lendlein and R. Langer, Science, 2002, 296, 1673; (b) A. Lendlein and S. Kelch, Angew. Chem., Int. Ed., 2002, 41, 2034; (c) C. Liu, H. Qin and P. T. Mather, J. Mater. Chem., 2007, $17,1543$.

10 (a) J. R. Capadona, K. Shanmuganathan, D. J. Tyler, S. J. Rowan and C. Weder, Science, 2008, 319, 1370; (b) K. Shanmuganathan, J. R. Capadona, S. J. Rowan and C. Weder, Progr. Polym. Sci., 2010 , in press.

11 (a) T. Heinzeller and J. Nebelsick, eds. Echinoderms; Taylor \& Francis Group, London, 2004; (b) T. Motokawa, Comp. Biochem. Physiol., Part B: Biochem. Mol. Biol., 1994, 109, 613.

12 (a) J. A. Trotter, J. Tipper, G. Lyons-Levy, K. Chino, A. H. Heuer, Z. Liu, M. Mrksich, C. Hodneland, W. Shannon Dillmore, T. J. Koob, M. M. Koob-Emunds, K. Kadler and D. Holmes, Biochem. Soc. Trans., 2000, 28, 357.

13 (a) J. A. Trotter and T. J. Koob, Matrix Biol., 1999, 18, 569; (b) G. K. Sulgit and R. E. Shadwick, J. Exp. Biol., 2000, 203, 1539.

14 B. Alberts, D. Bray, J. Lewis, M. Raff, K. Roberts and J. D. Watson, Molecular Biology of The Cell 3rd Edition, New York, NY, 1994.

15 (a) W. L. C. Rutten, Аnnu. Rev. Biomed. Eng., 2002, 4, 407; (b) A. B. Schwartz, Annu. Rev. Neurosci., 2004, 27, 487.
16 D. H. Szarowski, M. D. Andersen, S. Retterer, A. J. Spence, M. Isaacson, H. G. Craighead, J. N. Turner and W. Shain, Brain Res., 2003, 983, 23.

17 P. S. Belton, S. F. Tanner, N. Cartier and H. Chanzy, Macromolecules, 1989, 22, 1615.

18 M. De Souza Lima and R. Borsali, Macromol. Rapid Commun., 2004, 25, 771 .

19 R. T. Woodhams, G. Thomas and D. K. Rodgers, Polym. Eng. Sci., 1984, 24, 1166.

20 S. J. Eichhorn, C. A. Baillie, N. Zafeiropoulos, L. Y. Mwaikambo, M. P. Ansell, A. Dufresne, K. M. Entwistle, P. J. Herrera-Franco, G. C. Escamilla, L. Groom, M. Hughes, C. Hill, T. G. Rials and P. M. Wild, J. Mater. Sci., 2001, 36, 2107.

21 N. Rodriguez, W. Thielemans and A. Dufresne, Cellulose, 2006, 13, 261.

22 A. Sturcova, J. R. Davies and S. J. Eichhorn, Biomacromolecules, 2005, 6, 1055.

23 J. R. Capadona, O. van den Berg, L. Capadona, M. Schroeter, D. Tyler, S. J. Rowan and C. Weder, Nat. Nanotechnol., 2007, 2, 765.

24 O. van den Berg, J. R. Capadona and C. Weder, Biomacromolecules, 2007, 8, 1353.

25 J. R. Capadona, K. Shanmuganathan, S. Trittschuh, S. Seidel, S. J. Rowan and C. Weder, Biomacromolecules, 2009, 10, 712.

26 A. Dufresne, M. B. Kellerhals and B. Witholt, Macromolecules, 1999 , 32, 7396.

27 www.alzet.com/products/cfs_prep.php (08/04/2009).

28 X. M. Dong, J. F. Revol and D. G. Grey, Cellulose, 1998, 5, 19.

29 R. Rusli and S. J. Eichhorn, Appl. Phys. Lett., 2008, 93, 033111.

30 (a) D. Bondeson, A. Mathew and K. Oksman, Cellulose, 2006, 13, 171; (b) S. M. A. S. Azizi, F. Alloin, J. Y. Sanchez, N. El Kissi and A. Dufresne, Macromolecules, 2004, 37, 1386; (c) N. E. Marcovich, M. L. Auad, N. E. Bellesi, S. R. Nutt and M. I. Aranguren, J. Mater. Res., 2006, 21, 870; (d) A. Tubak, F. Snyder and K. Sandberg, United States Patent Number 4378381, 1983.

31 V. Favier, H. Chanzy and J. Y. Cavaillé, Macromolecules, 1995, 28, 6365.

32 N. Ljungberg, J.-Y. Cavaillé and L. Heux, Polymer, 2006, 47, 6285.

33 A. Dufresne, Compos. Interfaces, 2003, 10, 369.

34 M. Matos Ruiz, J. Y. Cavaillé, A. Dufresne, J. F. Gérard and C. Graillat, Compos. Interfaces, 2000, 7(2), 117.

35 T. S Zhao, K. D. Kreuer and T. V. Nguyen, eds. Advances in Fuel Cells: Elsevier publishers (2007) pp. 235-326.

36 J. C. Halpin and J. L. Kardos, J. Appl. Phys., 1972, 43, 2235.

37 M. Takayanagi, S. Uemura and S. Minami, J. Polym. Sci. Part C, 1964, 5, 113

38 N. Ouali, J. Y. Cavaillé and J. Pérez, Elastic Plast. Rubber Comp. Process Appl., 1991, 16, 55.

39 P. Hajji, J.-Y. Cavaillé, V. Favier, C. Gauthier and G. Vigier, Polym. Compos., 1996, 17, 612.

40 V. Favier, R. Dendievel, G. Canova, J. Y. Cavaillé and P. Gilormini, Acta Mater., 1997, 45, 1557.

41 A. Morin and A. Dufresne, Macromolecules, 2002, 35, 2190.

42 K. Najafi and J. F. Hetke, IEEE Trans. Biomed. Eng., 1990, 37, 474.

43 A. Hess, J. Dunning, J. Harris, J. R. Capadona, K. Shanmuganathan, S. J. Rowan, C. Weder, D. J. Tyler and C. A. Zorman, Proceedings of the 15th International Conference on Solid-state Sensors, Actuators and Microsystems, IEEE Transducers 2009, CO, USA. 